\title{
Anchor Ice and Benthic Disturbance in Shallow Antarctic Waters: Interspecific Variation in Initiation and Propagation of Ice Crystals
}

\author{
MARK DENNY ${ }^{1, *}$, KELLY M. DORGAN ${ }^{2} \uparrow$, DENNIS EVANGELISTA ${ }^{2}$, \\ ANNALIESE HETTINGER ${ }^{3}$, JAMES LEICHTER ${ }^{4}$, WARREN C. RUDER ${ }^{5,}$, \\ AND IDAN TUVAL ${ }^{6, \S}$ \\ ${ }^{1}$ Hopkins Marine Station of Stanford University, Pacific Grove, California 93950; ${ }^{2}$ Department of \\ Integrative Biology, University of California, Berkeley, California 94720; ${ }^{3}$ Bodega Marine Laboratory, \\ University of California Davis, Bodega Bay, California 94923; ${ }^{4}$ Scripps Institution of Oceanography, La \\ Jolla, California 92037; ${ }^{5}$ Department of Biomedical Engineering, Carnegie Mellon University, \\ Pittsburgh, Pennsylvania 15213; and ${ }^{6}$ Department of Applied Mathematics and Theoretical Physics, \\ University of Cambridge, Cambridge CB1, UK
}

\begin{abstract}
Sea ice typically forms at the ocean's surface, but given a source of supercooled water, an unusual form of ice-anchor ice-can grow on objects in the water column or at the seafloor. For several decades, ecologists have considered anchor ice to be an important agent of disturbance in the shallow-water benthic communities of McMurdo Sound, Antarctica, and potentially elsewhere in polar seas. Divers have documented anchor ice in the McMurdo communities, and its presence coincides with reduced abundance of the sponge Homaxinella balfourensis, which provides habitat for a diverse assemblage of benthic organisms. However, the mechanism of this disturbance has not been explored. Here we show interspecific differences in anchor-ice formation and propagation characteristics for Antarctic benthic organisms. The sponges $H$. balfourensis and Suberites caminatus show increased incidence of formation and accelerated spread of ice crystals compared to urchins and sea stars. Anchor ice also forms readily on sediments, from which it can grow and adhere to
\end{abstract}

\footnotetext{
Received 2 September 2010; accepted 31 May 2011.

* To whom correspondence should be addressed. E-mail: mwdenny@ stanford.edu

$\dagger$ Current address: Scripps Institution of Oceanography, La Jolla, CA 92037.

$\ddagger$ Current address: Department of Biomedical Engineering, Boston University, Boston, MA 02215.

$\S$ Current address: Department of Global Change Research, Mediterranean Institute for Advanced Studies, Balearic Islands, Spain.
}

organisms. Our results are consistent with, and provide a potential first step toward, an explanation for disturbance patterns observed in shallow polar benthic communities. Interspecific differences in ice formation raise questions about how surface tissue characteristics such as surface area, rugosity, and mucus coating affect ice formation on invertebrates.

\section{Introduction}

Shallow-water benthic communities in Antarctica are characterized by distinct zonation (Dayton et al., 1969; Dayton, 1989; Pearse et al., 1991). At depths less than 5-10 $\mathrm{m}$ (the shallow zone), annual sea ice scours the shore, and as a result, the benthic community is chronically depauperate. At depths greater than a few tens of meters (the deep zone), what little physical disturbance exists is caused by ice calved from glaciers (icebergs) sufficiently massive to scrape the seafloor. This disturbance is relatively rare in both space and time, and as a consequence, the deep-zone community is temporally stable and diverse (Pearse et al., 1991). In both shallow and deep zones, the agent of disturbance is ice as we normally encounter it-floating on the water's surface.

In McMurdo Sound in the Ross Sea, there is a third recognized zone between 5 and $33 \mathrm{~m}$, a zone that differs in two important ways. As with the shallow and deep zones, the community of this middle zone is shaped by disturbance 
from ice, but ice of an unusual type-anchor ice-that forms on the sea floor rather than at the sea surface (Pearse, 1962; Dayton et al., 1969, 1970; Dayton, 1989; Lock, 1990; Gutt, 2001; Gosnell, 2007). In contrast to the deep and shallow zones (Pearse et al., 1991), the anchor-ice zone at McMurdo has a benthic community that varies markedly through time (Dayton, 1989). In years when anchor-ice disturbance is low, the sponge Homaxinella balfourensis (Ridley and Dendy, 1886) recruits rapidly, and its presence as a foundation species promotes a burgeoning assemblage of sea stars, sea urchins, nemerteans, polychaetes, and pycnogonids (Dayton, 1989). However, in years when anchor-ice disturbance is high, $H$. balfourensis is rare or absent, and the epibenthic community is depleted (Dayton et al., 1969; Dayton, 1989). Anchor ice is thus the source of an intriguing — and ecologically important_interaction between the details of phase transitions in seawater and the morphology, materials properties, and species interactions of benthic plants and animals.

\section{Anchor-ice formation}

At atmospheric pressure and a typical salinity of $33 \mathrm{psu}$, it is thermodynamically favorable for seawater at its freezing point $\left(-1.81^{\circ} \mathrm{C}\right)$ to transition from its liquid phase to ice, its solid phase (Fujino et al., 1974; UNESCO, 1983; Lock, 1990; de Posdesta, 2002). Increasing pressure or salinity shifts the thermodynamic balance such that a lower temperature is required before seawater can freeze.

However, the fact that it is thermodynamically favorable for seawater to freeze does not ensure that the transition from seawater to ice will occur spontaneously. Typically, seawater must be cooled below its freezing point (that is, supercooled) before it will freeze (Lock, 1990; Matsumoto et al., 2002). Under controlled conditions in the laboratory, water can be supercooled by $40{ }^{\circ} \mathrm{C}$ and still remain liquid (Lock, 1990). In nature, the extent of supercooling required for ice formation is modified by the presence of solid particles in the water, which serve as nucleation sites for the initial formation of ice crystals known as frazil ice (Martin, 1981). When effective nucleation sites are available, frazil ice can be found in water supercooled by only about $0.01{ }^{\circ} \mathrm{C}$ (Osterkamp, 1978; Martin, 1981; Ashton, 1983; Lock, 1990). The effectiveness with which particles act as nucleating sites (and therefore their effectiveness in reducing the amount of supercooling required for freezing) depends on the surface properties of the particles (Lock, 1990).

Supercooling sets the stage for the interaction of ice with benthic communities in the anchor-ice zone. Typically, seawater in this zone is at thermodynamic equilibrium with surface ice at about -1.8 to $-1.9{ }^{\circ} \mathrm{C}$, depending on depth and salinity. However, water can be cooled in localized areas such as polynyas, where liquid seawater is in contact with cold air (Lock, 1990), or at depth under ice sheets (e.g.,
Robinson, 2004). Water cooled in these areas can subsequently be advected into the anchor-ice zone where, because it is below the local freezing point, it can fuel the production of anchor ice (Hunt et al., 2003). Some supercooled water may nucleate on particles in the water column or grow on small ice crystals scoured from surface sea ice, forming frazil ice. Alternatively, ice may nucleate on, or frazil ice may attach to, benthic structures (i.e., rocks, mud, detritus, or organisms), thereby forming anchor ice. Once formed, anchor ice, like other forms of sea ice, is stable as long as the temperature of the surrounding water remains at its freezing point. If the temperature decreases, additional anchor ice can accrete; if the temperature rises (as it periodically does during the Austral summer at McMurdo; Hunt et al., 2003), anchor ice melts.

Conditions amenable to anchor-ice formation are met sporadically in McMurdo Sound, the site of this study. Net circulation in the Sound is driven by a clockwise offshoot of the Ross Sea current, causing water to move southward along the east coast of the Sound (Littlepage, 1965; Barry and Dayton, 1988). Water then moves under the permanent Ross Ice Shelf, reappearing as a northward current moving along the west coast of the Sound. Superimposed on this mean motion is a diurnal tidal current (Barry and Dayton, 1988) that on occasion pulls water from deep under the Ross Ice Shelf and carries it into shallow water. Temperatures as low as $-2.15{ }^{\circ} \mathrm{C}$ have been recorded in the vicinity of McMurdo Station (Littlepage, 1965), although salt concentration may have been high enough that the water measured at this temperature was not supercooled. Supercooling of 0.01 to $0.05{ }^{\circ} \mathrm{C}$ is more common (Hunt et al., 2003). This subshelf water is presumably the source of supercooled water required for anchor-ice formation at McMurdo Station (Dayton, 1989; Hunt et al., 2003), although it remains unclear why, at this site, anchor ice forms only above a depth of $33 \mathrm{~m}$. Dayton (1989) documented interdecadal variability in the formation of anchor ice at McMurdo Station and speculated that this variation was driven by variation in large-scale oceanographic conditions. Presumably, the local realization of this large-scale pattern is yearto-year variation in the delivery of supercooled water to the anchor-ice zone.

\section{Potential impacts of anchor ice on organisms}

As far as we know, details of the interactions of anchor ice with organisms have not been studied. However, we speculate that, when present, anchor ice can act as a source of ecological disturbance through several mechanisms:

1. If the formation of ice on the exterior of an animal or alga causes its interior to freeze, the resulting damage may injure or kill the organism. Freezing of internal tissues initiated by contact with external ice is a particularly serious threat to fish, which maintain 
their bodies at a lower osmotic concentration (and therefore a higher freezing point) than that of seawater, and Antarctic fish have evolved a variety of means to cope with the threat (e.g., Cheng and Dietrich, 2007). In contrast, marine algae and invertebrates typically have bodies that are isosmotic with seawater (Schmidt-Nielsen, 1997), and therefore have no greater tendency to freeze than does the seawater around them. Problems arise only when seawater supercools and freezes, in which case organisms can freeze as well. Some intertidal invertebrates in cold temperate regions (e.g., the mussel Mytilus edulis) can freeze, thaw, and survive (Kanwisher, 1955; Aarset, 1982; Aunaas, 1985), but as far as we know, this capability has not been investigated in Antarctic benthic invertebrates.

2. Anchor ice on organisms can disturb benthic communities by inhibiting suspension feeding or light interception by sessile organisms and foraging by motile animals. The extent to which anchor ice interferes with feeding, photosynthesis, and foraging has not been explored.

3. By virtue of increasing organisms' effective area and displacement, anchor ice forming on organisms can increase the drag and acceleration reaction forces imposed by moving water (Vogel, 1994) and thereby increase the risk of damage or dislodgment (Denny, 1988). Although the hydrodynamic forces imposed on Antarctic benthic organisms have not been investigated, currents in this habitat are relatively slow $(<0.11 \mathrm{~m} / \mathrm{s}$; Barry and Dayton, 1988), and removal by hydrodynamic forces thus seems unlikely.

4. Additionally, anchor ice can cause disturbance through the application of a buoyant force. When seawater freezes, its density decreases from 1027 $\mathrm{kg} / \mathrm{m}^{3}$ to about $917 \mathrm{~kg} / \mathrm{m}^{3}$ (Denny, 1993). As a result, each cubic meter of anchor ice exerts a buoyant force of about $1100 \mathrm{~N}$ ( 50 pounds) on the objects to which it is attached. If the buoyant force exerted by attached anchor ice exceeds the maximum tensile strength of the object or its attachment to the seafloor, part or all of the object (mud, rock, seaweed, or animal) is pulled loose from the seafloor and carried upward to the surface sea ice above. If not released by local melting, impact, water flow, or (for an animal) by its exertions, an organism dislodged by anchor ice is permanently incorporated into the surface sea ice (Pearse, 1962; Dayton et al., 1969).

Dayton et al. (1969), Dayton (1989), and Pearse et al. (1991) speculate that disturbance from anchor ice (in one or several of the forms cited above) accounts for the depthdependent zonation and annual and decadal variation in the shallow-water benthic community at McMurdo Sound.
Similar effects have been reported from polar regions worldwide (Lenihan and Oliver, 1995; Gutt, 2001). These reports note parenthetically that susceptibility to disturbance by anchor ice apparently varies among species: at McMurdo Sound, sponges are disturbed most, whereas abundances of some other sessile epibenthic organisms (anemones, alcyonarians, actinians, stoloniferans, and ascideans) seem unaffected by the presence of anchor ice (Dayton, 1989; Gutt, 2001).

Due both to the extreme conditions of the environment in which it occurs (August-December in Antarctica) and to the apparently episodic nature of the process (Dayton et al., 1969; Dayton, 1989; Gutt, 2001), the formation of anchor ice on benthic organisms has not been directly observed in nature. Here we report on laboratory experiments exploring the process of anchor-ice formation on benthic organisms and show that the tendency to support anchor-ice formation varies among species. Although limited in scope, these results nonetheless serve as a first step toward a more complete understanding of the process of anchor-ice formation in nature, providing a potential mechanistic explanation of interspecific variation in anchor-ice disturbance, and thereby of the pattern of temporal variability in benthic community composition in anchor-ice zones.

\section{Materials and Methods}

Experiments were conducted at McMurdo Station on Ross Island, Antarctica $\left(77^{\circ} 51^{\prime} \mathrm{S}, 166^{\circ} 40^{\prime} \mathrm{E}\right)$ in January 2010. Scuba divers collected benthic animals and samples of benthic substratum (a feltwork of mud and sponge spicules) at depths of 10 to $25 \mathrm{~m}$ from a site beneath the multiyear surface sea ice adjacent to the station. Organisms tested included the sponges Homaxinella balfourensis, Mycale acerata, and Suberites caminatus; the sea urchin Sterechinus neumayeri; the sea star Odontaster validus; the anemone Isotealia antarctica; and the soft coral Alcyonium antarcticum. In addition, we collected samples of the benthic red alga Phyllophora antarctica at depths of 15 and $25 \mathrm{~m}$ at Cape Evans, Ross Island, approximately $25 \mathrm{~km}$ north of McMurdo Station. All organisms were held in flowing seawater at $-1{ }^{\circ} \mathrm{C}$ until used.

\section{Formation of anchor ice}

We placed a small sample $(<2 \mathrm{~cm}$ maximum dimension) of tissue or substratum in an open, unstirred 250-ml polypropylene beaker and filled the container with $150 \mathrm{ml}$ of seawater at $1{ }^{\circ} \mathrm{C}$. Multiple containers were arranged on a fiberglass tray, and the tray was then placed on a wire mesh shelf in a $-20{ }^{\circ} \mathrm{C}$ walk-in freezer. We observed each container as it cooled. In each experiment, we included five beakers of each specimen, along with containers holding only seawater to act as controls, and temperature was mea- 


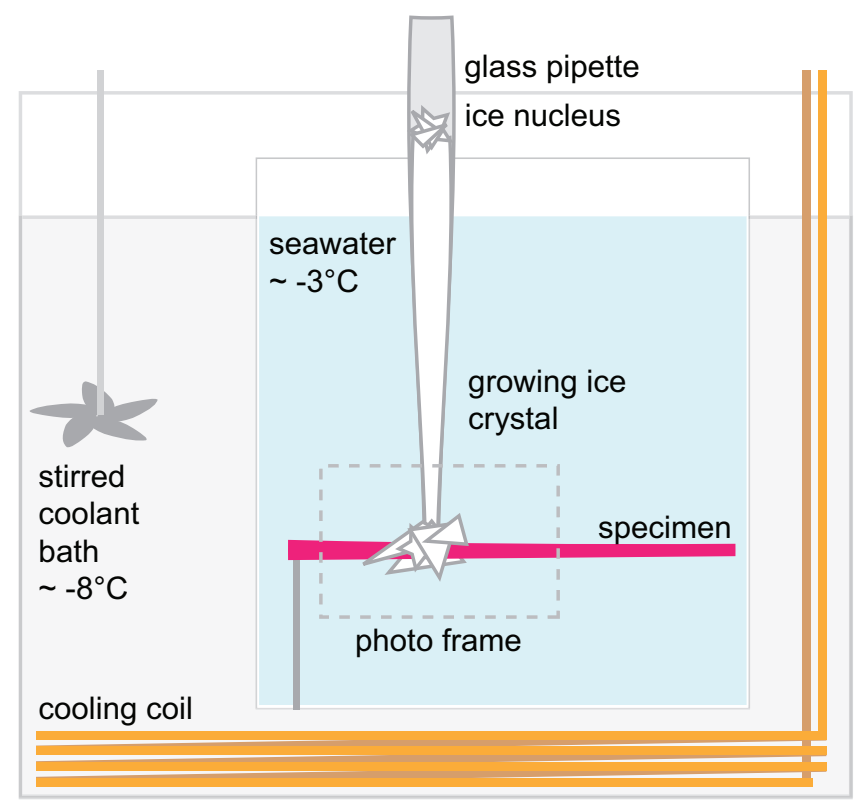

Figure 1. A diagram of the apparatus used to observe the interaction of single growing ice crystals with benthic invertebrates and algae.

sured in multiple containers with alcohol thermometers. We repeated the experiment 6-9 times for each of 11 species.

Within 6-10 min of placement in the freezer, ice was always observed to form on the surface edges. This always occurred at the top of the beaker, when water temperature reached $-4{ }^{\circ} \mathrm{C}$. At the same time, in some samples, ice nucleation (or, alternatively, growth from nuclei adhered to the surface) was observed on the tissue, below the surface. The presence or absence of visible ice growth originating on the tissue was recorded as a gross measure of propensity to form anchor ice. Differences among species were analyzed using a Kruskal-Wallis rank sum test and multiple comparison tests implemented in R, ver. 2.13.1 (R Development Core Team, 2011).

\section{Ice propagation after contact with a single ice crystal}

The experiments described above did not allow us to control the temperature at which ice formed on tissues or to observe the details of formation and subsequent propagation. To partially circumvent these limitations, we designed an apparatus (based on that of Braslavsky and Lipson, 1999) to explore the interaction of a single, growing crystal of ice with each of our test species under controlled conditions (Fig. 1).

We immersed a transparent test chamber containing still seawater in a vigorously stirred coolant bath at a temperature of $-8.0{ }^{\circ} \mathrm{C}$. The specimen to be tested was mounted horizontally in the center of the test chamber where it could be photographed from the side. We modified a glass Pasteur pipette by cutting away most of its wider radius stem, leaving a shortened stem that tapered into a glass capillary tube. The pipette was suspended above the test specimen and allowed to fill with seawater, and we monitored the temperature of water near the tip of the capillary tube by using a thermocouple (40-gauge copper-constantan wires) inserted into the tube (model HH23 thermocouple thermometer, Omega Engineering, Stamford, CT). Water in the test chamber was gently stirred with another thermocouple, which was used to monitor temperature outside the pipette. When the water reached $-3.0{ }^{\circ} \mathrm{C}$ for both thermocouples, the thermocouples were removed, a small chip of freshwater ice was introduced into the stem of the pipette to serve as a nucleation site, and the resulting ice crystal grew down the capillary tube. Upon reaching the tip of the tube, a single, planar, feather-like (dendritic) crystal grew into the test chamber and contacted the test specimen.

We recorded time-lapse movies of the ensuing interaction using a Nikon D300S camera with a $105-\mathrm{mm}$ macro lens (Nikon Inc., Tokyo, Japan) operated at 1 frame/s. We then assembled individual frames using Quick Time ver. 7.6 (Apple Inc., Cupertino, CA). Close examination of the recorded images allowed us to place each test into one of three categories. In the first category, the touch of the growing ice crystal caused the test specimen to act as a secondary nucleation site from which multiple new crystals grew rapidly. In the second category, the growing crystal changed its direction of growth, extending along the surface of the test specimen, and few new crystals were initiated. In the third category, there was no apparent interaction of the growing ice crystal with the test specimen: the initial ice crystal continued to grow, spreading around the test specimen, but no new crystals were initiated. We performed tests on 4-11 samples of each type of specimen (a single seaurchin spine and about 2-3-cm-long segments of sea-star arm, sponge, anemone, or soft-coral tissue) and analyzed variation among sample types using a contingency table and a $\chi^{2}$ test (Zar, 1998; Krebs, 1998).

To further quantify the ice-propagation potential of $H$. balfourensis, S. neumayeri, O. validus, I. antarctica, and $P$. antarctica, we analyzed the time-lapse images of each experiment to measure the rate at which ice spread along the surface of the specimen in association with the growth and contact of the single ice crystal. We subtracted the image of each specimen prior to contact from subsequent images to highlight crystal growth, allowing us to accurately locate the "front" of propagation as it moved along the plane of the specimen's surface (Fig. 2). We tracked the speed of this front throughout the experiment, and noted the maximum rate of growth. Lengths were scaled using the known diameter of the capillary tube from which the initial crystal grew. We analyzed variation in maximum crystal growth rate among samples, using a one-way analysis of variance (ANOVA; Zar, 1998). 

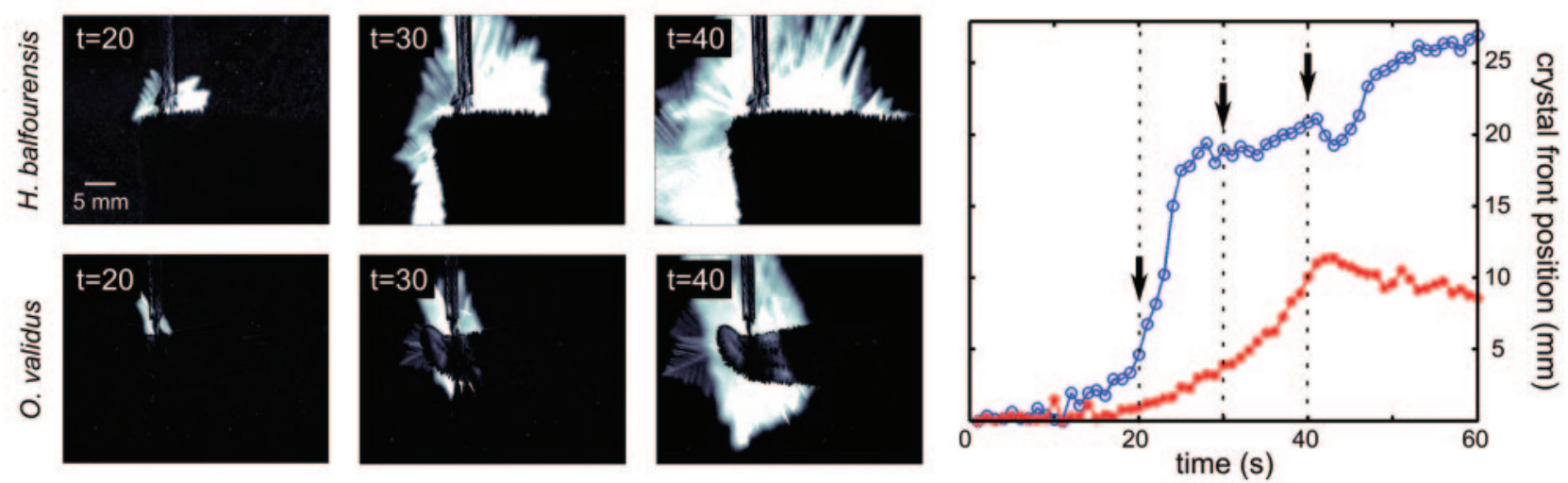

Figure 2. Representative examples of the interaction between a single growing ice crystal and benthic invertebrates. Left panels: single frames from the contrast-enhanced time series of interaction. Upper panels, the sponge, Homaxinella balfourensis, which readily nucleates ice formation; lower panels, the sea star Odontaster validus, which does not. Right panel: the time course of the advancement of the ice "front" for $H$. balfourensis (blue line) and $O$. validus (red line). Arrows denote times at which the frames in the left panels were taken. The apparent retreat of the ice front for times $>40 \mathrm{~s}$ is due to the effects of out-of-plane crystals interfering with the front-following algorithm and does not affect measurement of the maximum rate of crystal growth.

\section{Interaction with ice on the substratum}

The experiments described above quantify the interaction of supercooled seawater with various material samples in isolation. In nature, benthic organisms encounter supercooled water while they are also in contact with the substratum. To recreate more of what would be encountered in nature, we observed the interaction of anchor ice with whole organisms in tanks containing natural substratum collected from the field.

To this end, we layered McMurdo Sound sediment on the bottom of an aquarium $(30 \times 60 \times 45 \mathrm{~cm})$, filled the aquarium with seawater, and allowed any suspended sediment to settle overnight. The sides of the aquarium were covered with neoprene rubber foam, insulating them from convective cooling by the surrounding air. This encouraged preferential formation of anchor ice on the uninsulated bottom of the tank, which was more rapidly cooled by conduction of heat to the cold table below. Test organisms (H. balfourensis, S. neumayeri, and $O$. validus) were then introduced into the tank, the tank was placed in a walk-in freezer at $-20^{\circ} \mathrm{C}$, and water temperature was measured with a thermocouple thermometer. As in the other experiments, when water in the tank reached approximately $-3{ }^{\circ} \mathrm{C}$, anchor ice began to form, and we observed the interaction of this ice with each organism. The experiment was repeated five times with a total of 10 urchins, 14 sea stars, and 5 pieces of sponge.

\section{Interaction with frazil ice}

As noted previously, ice can also nucleate in supercooled water away from the substratum. If the water is flowing during this nucleation, the resulting frazil ice may adhere to epibenthic organisms, collecting on exposed surfaces or drifting alongside and underneath. For this test, we placed organisms in a $30 \times 30 \times 40-\mathrm{cm}$ seawater aquarium with clear acrylic plastic sides and a steel sheet-metal bottom similar to the apparatus of Weissenberger and Grossmann (1998). The tank was stirred using an overhead stirrer (Wheaton model 903475 ) placed in a $-20{ }^{\circ} \mathrm{C}$ walk-in freezer to cool, and its temperature measured with a thermocouple thermometer. When the temperature of the water reached -2.1 to $-2.3{ }^{\circ} \mathrm{C}$, frazil ice readily formed and continued to form for several minutes, during which the temperature in the tank remained fairly constant. Prior to frazil-ice formation, we introduced test organisms (H. balfourensis, S. neumayeri, and $O$. validus) into the tank, and we noted the interaction of these organisms with frazil ice. The experiment was repeated four times for a total of four urchins, three sponges, and two sea stars.

\section{Results}

\section{Formation of anchor ice}

Anchor-ice formation varied significantly among the species tested (Fig. 3; Kruskal-Wallis rank sum test, $\chi^{2}=67.9$, $\mathrm{df}=10, P \ll 0.001)$. The sponges Suberites caminatus and Homaxinella balfourensis and both spicule-laden and spicule-free muds formed anchor ice in nearly every trial. In contrast, the soft coral Alcyonium antarcticum, spines of the urchin Sterechinus neumayeri, and the sponge Mycale acerata seldom initiated ice formation on tissue, and were statistically indistinguishable from plain seawater in a clean polypropylene beaker (which always froze from the top and never grew ice on submerged surfaces). The seaweed Phyllo- 


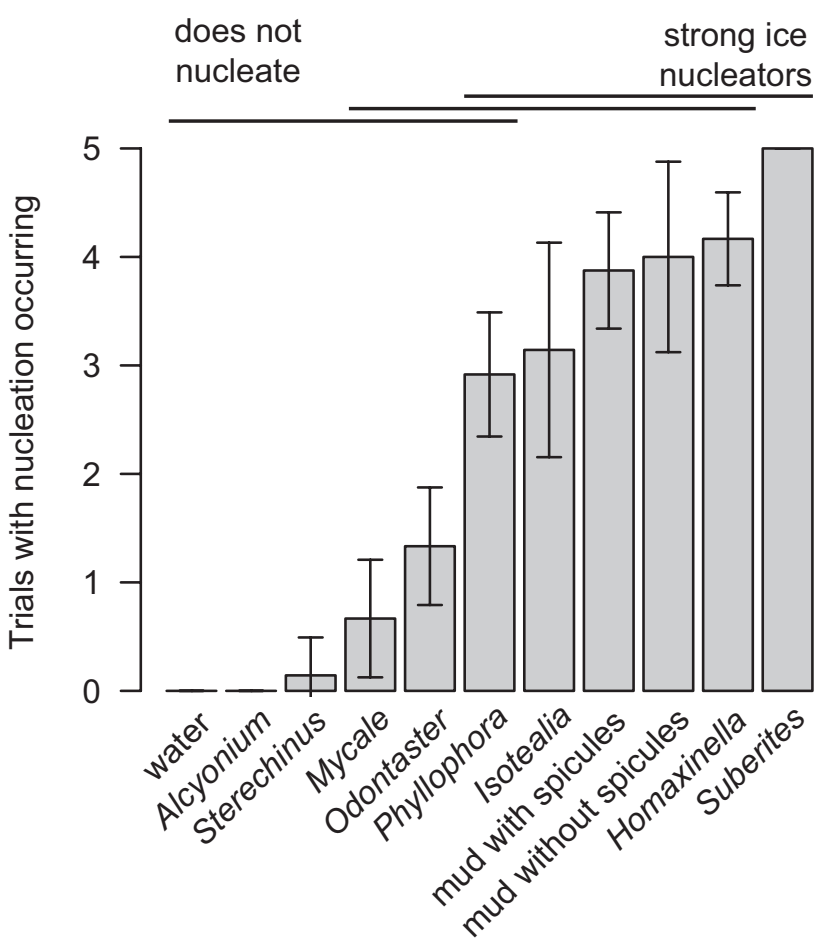

Figure 3. Formation of anchor ice varies significantly among the species tested (Kruskal-Wallis rank sum test, $\chi^{2}=67.9$, df $=10, P=1.137 \mathrm{x}$ $10^{-10}$ ). The sponges Sterechinus caminatus and Homaxinella balfourensis and spicule-laden and spicule-free muds (right) formed anchor ice in nearly every trial. In contrast, the soft coral Alcyonium antarctica, spines of the urchin Suberites neumayeri, and the sponge Mycale acerata never initiated ice formation (left). Horizontal bars denote groups that are statistically indistinguishable. Error bars are 95\% confidence limits.

phora antarctica initiated ice formation in about $60 \%$ of trials.

\section{Secondary nucleation and propagation following contact} with a single ice crystal

Interaction with a single, growing ice crystal varied nonrandomly among species (Table $1, \chi^{2}=79.6, \mathrm{df}=16, P \ll$ 0.001). Most species fell into Category 2 , in which the growing crystal clearly was affected by contact with the specimen surface but few new crystals were initiated. The sponges $S$. caminatus and $H$. balfourensis readily initiated new crystals (Category 1), whereas $M$. acerata never initiated new crystals (Category 3). M. acerata is typically coated with a thick layer of mucus, whereas $S$. caminatus and $\mathrm{H}$. balfourensis are not. The growing crystal simply grew around spines of the urchin S. neumayeri (Category 3).

The speed of crystal propagation along the specimen surface varied significantly among species (Fig. 4; $F(4,25)=36.6, P \ll 0.001)$, and extension speed was positively correlated with the probability of initiating ice formation in beakers (Fig. 3; $P \ll 0.001$, determined by a bootstrap estimate of the distribution of the Spearman cor-
Table 1

Response of mud and various biological objects to contact by a single growing ice crystal

\begin{tabular}{lrcrr}
\hline \hline & \multicolumn{4}{c}{ Nucleation } \\
\cline { 2 - 5 } \multicolumn{1}{c}{ Species } & Extensive & Moderate & None & Total \\
\cline { 2 - 6 } Suberites caminatus, sponge & 4 & 0 & 0 & 4 \\
Homaxinella balfourensis, sponge & 10 & 0 & 0 & 10 \\
McMurdo mud & 5 & 0 & 0 & 5 \\
Mycale acerata, sponge & 0 & 4 & 7 & 11 \\
Phyllophora antarctica, seaweed & 5 & 0 & 0 & 5 \\
Sterechinus neumayeri, urchin & 0 & 0 & 10 & 10 \\
Odantaster validus, sea star & 0 & 0 & 5 & 5 \\
Isotealia antarctica, anemone & 0 & 5 & 5 & 10 \\
Alcyonium antarcticum, soft coral & 0 & 2 & 3 & 5 \\
\multicolumn{1}{c}{ Totals } & 24 & 11 & 30 & 65 \\
\hline
\end{tabular}

relation coefficient). In other words, increased probability of initiating new crystals is associated with increased rate of crystal extension.

\section{Interaction with ice on the substratum}

In the tank containing sediment and organisms, anchor ice first formed on the substratum (not surprising, as the bottom surface of the tank cooled more rapidly than the interior). Ice then grew until contacting an organism or nucleated on the organism itself. Anchor ice growing from the substratum interacted differently with different animals.

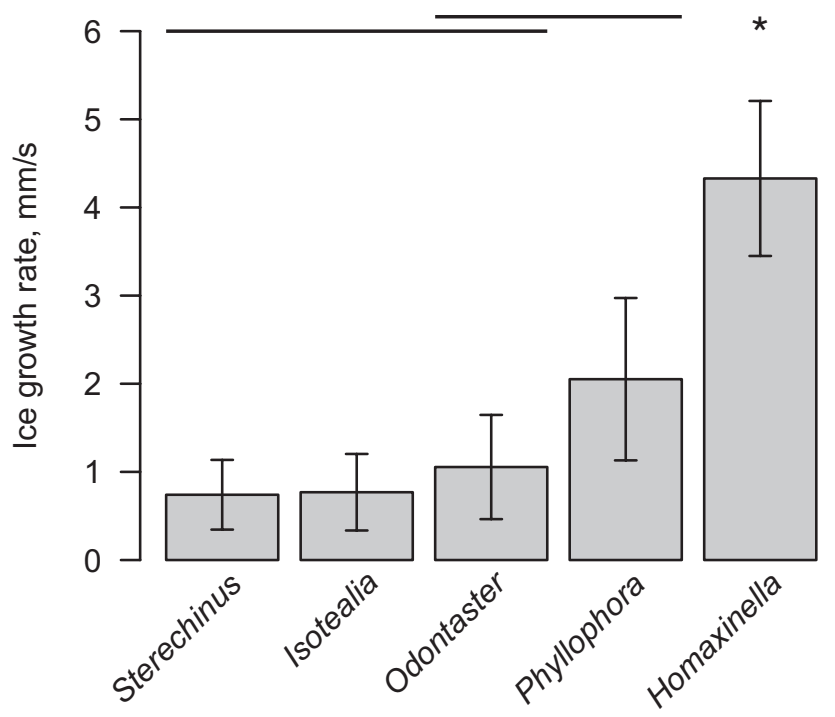

Figure 4. Mean speed of crystal extension along the specimen surface varied significantly among species $(F(4,25)=36.6, P \ll 0.001)$. Speed was greatest in the sponge Homaxinella balfourensis, which readily nucleates ice formation. Horizontal bars denote groups that are statistically indistinguishable, and the asterisk indicates that $H$. balfourensis is distinguishable from all others. Error bars are 95\% confidence limits. 
Substratum-initiated crystals adhered to and engulfed all five $H$. balfourensis specimens tested, and ice was found on parts of some sponges not in contact with the substratum. (Initial formation of ice was not directly observed because of impeded visualization from insulation on the side and ice on the surface of the tank.) Ice adhered to the oral spines of S. neumayeri in all of the 10 animals tested, and 3 of the 10 were stuck to the substratum by ice. A few urchins had ice crystals on spines on the side of their bodies, and one had a large ice crystal on an aboral spine. We observed several urchins rotating their spines, dislodging attached ice crystals. Substratum-initiated crystals adhered primarily to the ambulacral groove of Odontaster validus near the tips of the arms, although a few sea stars also had ice plates on the aboral surface. Sea stars were observed to curl the tips of their arms up off the icy substratum.

\section{Interaction with frazil ice}

Frazil ice suspended in the water column collected alongside and underneath organisms such as the urchin $S$. neumayeri. The resulting "snowdrifts" seemed to be due to mechanical entrapment rather than to adhesion of the frazil ice to the organism, as movement of the urchin caused ice to easily dislodge and float away. Subsequent adhesion of frazil ice or initiation of ice formation on tissues may occur in the field under longer time periods and more varying temperatures than in our experiments. Frazil ice also collected around sponges, and close examination of sponges after the experiments showed ice crystals attached to the tissue, either from adhesion of frazil ice or nucleation of ice on the tissue. Frazil ice did not, however, collect around or adhere to the sea star $O$. validus.

\section{Discussion}

Because ice is substantially less dense than liquid water, sea ice characteristically forms at the interface between ocean and air. Only under unusual circumstances can anchor ice accumulate on the seafloor. In particular, the formation of anchor ice requires both a source of supercooled water and sites either in the water column or on the seafloor that can nucleate that supercooled water to initiate ice formation. As noted in the Introduction, previous studies have demonstrated that supercooled water is sporadically present at McMurdo Station, although at temperatures above those needed to form anchor ice in the laboratory. In this study, we focused on the interaction of organisms with supercooled water and their ability to support ice formation.

Anchor-ice formation can be initiated in the anchor-ice zone at McMurdo. First, and perhaps foremost, small ice crystals in the water column might initiate anchor-ice formation when they contact the substratum or benthic organisms. Furthermore, spicule-laden mud comprises much of the substratum at McMurdo, and it itself is capable of initiating anchor-ice formation (Table 1 and Fig. 2). Thus, even in the absence of benthic algae and animals, anchor ice can form when supercooled water is present. While this might suggest that an individual's propensity to support anchor-ice formation is of secondary importance, the location of anchor-ice initiation, and the subsequent accumulation of anchor ice, may nonetheless be affected by benthic organisms, and could thereby have ecological significance. It is here that our results come to the fore. Among the species we tested, two sponges showed by far the greatest likelihood of initiating anchor-ice formation and propagating growing crystals. If, in nature, this proclivity renders these species particularly susceptible to subsequent disturbance, it would help to explain why sponge populations at this site are differentially affected by anchor ice.

There are several caveats to this suggestion. First, as noted, we have no direct evidence as to whether anchor ice is deleterious or beneficial to sponges. Although it is difficult to imagine how anchor-ice formation could benefit feeding of sponges, it is possible that ice nucleation acts to protect sponge cells from freezing. For example, many terrestrial organisms use extracorporeal ice nucleation as a mechanism to avoid intracellular damage (Duman et al., 1991). Rapid formation of ice outside cells draws water from within cells, reducing the likelihood that cells themselves will freeze and be damaged. Whether this mechanism is effective in sponges is not known. Although research on the subject is scant, sponges-unlike terrestrial organisms - are thought to be isosmotic with their surroundings (e.g., Lange, 1965; Prosser, 1967). We did not examine the occurrence and extent of physiological damage to tissues caused by ice formation.

A second caveat is that buoyant disturbance by anchor ice depends both on the amount of ice an organism accumulates and on the ability of the organism (and the substratum to which it adheres) to remain attached to the seafloor. To our knowledge, the adhesive strength of sponges (or any other benthic organism) has not been measured in the Antarctic. Thus, even if sponges preferentially accumulate anchor ice, it is far from certain that they are preferentially dislodged.

Finally, our laboratory experiments with single crystals were conducted in water supercooled by approximately $1.19^{\circ} \mathrm{C}\left(-1.81{ }^{\circ} \mathrm{C}\right.$ to $\left.-3.00{ }^{\circ} \mathrm{C}\right)$ in contrast to the $0.01{ }^{\circ} \mathrm{C}$ to (possibly) $0.34{ }^{\circ} \mathrm{C}$ of supercooling recorded in the water at McMurdo (Littlepage, 1965; Hunt et al., 2003). This greater degree of supercooling was necessary to reliably initiate growth of a test crystal (a discrepancy long noted in the literature [Osterkamp, 1978], but not definitively explained), and it is possible that the interaction of crystal and organism differs with the degree of supercooling. In particular, the speed of growth of ice crystals increases with the magnitude of supercooling (Braslavsky and Lipson, 1999).

Further research on how anchor ice affects organisms over longer time periods and under more natural conditions 
is needed to draw conclusions about the ecological impacts of our findings. It does, however, seem likely that although anchor ice can impact organisms by initially forming on the substratum rather than on tissues, initiation on tissues would result in increased amounts of ice and in greater difficulty for the organism in removing ice, either actively or passively. This difficulty would be compounded for sponges by their lack of mobility. We observed movements of urchin spines that dislodged frazil ice and broke ice crystals that formed around spines. We did not, however, specifically explore mechanisms of ice removal and their dependence on the ability of the organism to initiate and propagate ice formation.

Aside from the potential biological implications of interspecific variability in the ability to initiate ice formation, the variation we have documented raises basic questions about the initiation process itself. Why, for instance, do urchin spines not initiate ice formation whereas sponges do? Note that there is variation even within the sponge species tested as to their ice-forming characteristics. H. balfourensis and $S$. caminatus readily initiated ice formation, while $M$. acerata did not. Lack of ice formation in M. acerata may be tied to the copious mucus produced by this species, in sharp contrast to the relatively slimeless others. Can mucus really serve as a mechanism to avoid ice formation? More research is necessary before the species-to-species variation in ice formation measured here can be directly tied to specific characteristics of tissues.

\section{Conclusions}

The ability to initiate and propagate ice crystals from supercooled seawater varies substantially among benthic species that occupy the Antarctic anchor-ice zone. The sponges Homaxinella balfourensis and Suberites caminatus show increased incidence of ice formation, and $\mathrm{H}$. balfourensis exhibits an accelerated spread of ice crystals compared to urchins and sea stars. This variation has the potential to affect the interaction of these species with anchor ice, and thereby to affect the community ecology of this zone. The laboratory results reported here are consistent with field observations of the pattern of benthic disturbance, and form a tentative first step toward understanding the full interaction of polar benthic organisms with supercooled water.

\section{Acknowledgments}

This study was undertaken as part of the NSF-sponsored course in Integrative Biology (OPP 0504072). We thank Donal Manahan and Deneb Karentz for organizing the course, the staff of McMurdo Station for their support, and Judith Connor for assistance in collecting algae. J. Pearse and two anonymous reviewers provided invaluable comments on the manuscript. D.E. acknowledges the support of the UC Berkeley Chancellor's Fellowship, the NSF IGERT program, and equipment loaned by the Berkeley Center for Integrative Biomechanics Education and Research (CIBER). K.M.D. acknowledges support from NSF grant IOS-0642249 to M.A.R. Koehl. A.H. acknowledges support from a NSF GK-12 fellowship. W.C.R acknowledges support from ONR grant N000140910215 to P.R. LeDuc.

\section{Literature Cited}

Aarset, A. V. 1982. Freezing tolerance in intertidal invertebrates. Comp Biochem. Physiol. 73A: 571-580.

Ashton, G. D. 1983. Frazil ice. Pp. 271-290 in Theory of Dispersed Multiphase Flow, R. E. Meyer, ed. Proceedings of an advanced seminar conducted by the Mathematics Research Center, the University of Wisconsin-Madison, May 26-28, 1982. Academic Press, New York.

Aunaas, T. 1985. Nucleating agents in the haemolymph of an intertidal mollusk tolerant to freezing. Experientia 38: 1456-1457.

Barry, J. P., and P. K. Dayton. 1988. Current patterns in McMurdo Sound, Antarctica, and their relationship to local biotic communities Polar Biol. 8: 367-376.

Braslavsky, I., and S. G. Lipson. 1999. The double-pyramid structure of dendritic ice growing from supercooled water. J. Cryst. Growth 56: 198-199.

Cheng, C-H. C., and H. W. Dietrich. 2007. Molecular ecophysiology of Antarctic notothenioid fishes. Phil. Trans. R. Soc. B 362: 22152232.

Dayton, P. K. 1989. Interdecadal variation in antarctic sponge and its predators from oceanographic climate shifts. Science 245: $1484-$ 1486

Dayton, P. K., G. A. Robilliard, and A. L. DeVries. $1969 . \quad$ Anchor ice formation in McMurdo Sound, Antarctica, and its biological effects. Science 163: 273-274.

Dayton, P. K., G. A. Robilliard, and R. T. Paine. 1970. Benthic faunal zonation as a result of anchor ice at McMurdo Sound, Antarctica. Pp. 244-258 in Antarctic Ecology, Vol. 1, M. W. Holgate, ed. Academic Press, New York.

Denny, M. W. 1988. Biology and the Mechanics of the Wave-Swept Environment. Princeton University Press, Princeton.

Denny, M. W. 1993. Air and Water: The Biology and Physics of Life's Media. Princeton University Press, Princeton.

de Podesta, M. 2002. Understanding the Properties of Matter. Taylor \& Francis, London.

Duman, J. G., D. W. Wu, L. Xu, D. Tursman, and T. M. Olsen. 1991. Adaptations of insects to subzero temperatures. Q. Rev. Biol. 66: 387-410

Fujino, K, E. L. Lewis, and R. G. Perkins. 1974. The freezing point of seawater at pressures up to 100 bars. J. Geophys. Res. 79: 1792-1797.

Gosnell, M. 2007. Ice: The Nature, the History, and the Uses of an Astonishing Substance. University of Chicago Press, Chicago.

Gutt, J. 2001. On the direct impact of ice on marine benthic communities, a review. Polar Biol. 24: 553-564.

Hunt, B. M., K. Hoefling, and C.-H. C. Cheng. 2003. Annual warming episodes in seawater temperatures in McMurdo Sound in relationship to endogenous ice in notothenioid fish. Antarct. Sci. 15: 333-338.

Kanwisher, J. W. 1955. Freezing in intertidal animals. Biol. Bull. 109: $56-63$.

Krebs, C. J. 1998. Ecological Methodology, 2nd ed. Benjamin Cummings, Menlo Park, CA

Lange, R. 1965. The osmotic function of free ninhydrin positive substances in the sponge Halichondria panacea (Pallas) and the coelenterate Metridium senile (L.). Reports from the Fourth Scandinavian Congress. Cell Res. 4: 40-41.

Lenihan, H. S., and J. S. Oliver. 1995. Anthropogenic and natural 
disturbances to marine benthic communities in Antarctica. Ecol. Appl. 5: 311-326.

Littlepage, J. L. 1965. Oceanographic investigations in McMurdo Sound, Antarctica. Pp. 1-37 in Biology of the Antarctic Seas II, G. A. Llano, ed. Antarctic Research Series, Vol. 5. American Geophysical Union, Washington, D.C.

Lock, G. S. H. 1990. The Growth and Decay of Ice. Cambridge University Press, Cambridge.

Martin, S. 1981. Frazil ice in rivers and oceans. Annu. Rev. Fluid Mech. 13: $379-397$.

Matsumoto, M., S. Saito, and I. Ohmine. 2002. Molecular dynamics simulation of the ice nucleation and growth process leading to water freezing. Nature 416: 409-413.

Osterkamp, T. E. 1978. Frazil ice formation: a review. J. Hydraulics Div. ASCE 104: 1239-1255.

Pearse, J. S. 1962. Letters. Sci. Am. 207(5): 12.

Pearse, J. S., J. B. McClintock, and I. Bosch. 1991. Reproduction of Antarctic marine invertebrates: tempos, modes, and timing. Am. Zool. 31: $65-80$.
Prosser, C. L. 1967. Ionic analyses and effects of ions on contractions of sponge tissues. Z. Vgl. Physiol. 54: 109-120.

R Development Core Team. 2011. R: A language and environment for statistical computing. R Foundation for Statistical Computing, Vienna Austria. [Online]. Available http://www.R-project.org.

Robinson, N. J. 2004. An oceanographic study of the cavity beneath the McMurdo Ice Shelf, Antarctica. M.Sc. thesis, School of Earth Sciences, Victoria University of Wellington, Wellington, New Zealand.

Schmidt-Nielsen, K. 1997. Animal Physiology: Adaptation and Environment, 4th ed. Cambridge University Press, Cambridge.

UNESCO. 1983. Algorithms for computation of fundamental properties of seawater. UNESCO Tech. Pap. Mar. Sci. 44: 1-55.

Vogel, S. 1994. Life in Moving Fluids. Princeton University Press, Princeton.

Weissenberger, J., and S. Grossmann. 1998. Experimental formation of sea ice: importance of water circulation and wave action for incorporation of phytoplankton and bacteria. Polar Biol. 20: 178-188.

Zar, J. H. 1998. Biostatistical Analysis, 4th ed. Prentice Hall, Englewood Cliffs, NJ. 